\title{
GCU
}

Glasgow Caledonian

University

University for the Common Good

\section{Using micro-geography to understand the realisation of wellbeing: a qualitative GIS study of three social enterprises}

Farmer, Jane; Kamstra, Peter; Brennan-Horley, Chris; De Cotta, Tracy; Roy, Michael; Barraket, Jo; Munoz, Sarah-Anne; Kilpatrick, Sue

Published in:

Health and Place

DOI:

10.1016/j.healthplace.2020.102293

Publication date:

2020

Document Version

Author accepted manuscript

Link to publication in ResearchOnline

Citation for published version (Harvard):

Farmer, J, Kamstra, P, Brennan-Horley, C, De Cotta, T, Roy, M, Barraket, J, Munoz, S-A \& Kilpatrick, S 2020

'Using micro-geography to understand the realisation of wellbeing: a qualitative GIS study of three social enterprises', Health and Place, vol. 62, 102293. https://doi.org/10.1016/j.healthplace.2020.102293

\section{General rights}

Copyright and moral rights for the publications made accessible in the public portal are retained by the authors and/or other copyright owners and it is a condition of accessing publications that users recognise and abide by the legal requirements associated with these rights.

Take down policy

If you believe that this document breaches copyright please view our takedown policy at https://edshare.gcu.ac.uk/id/eprint/5179 for details

of how to contact us. 


\title{
Using micro-geography to understand the realisation of wellbeing: a qualitative GIS study of three social enterprises
}

\begin{abstract}
Social enterprises are promoted as a method of welfare reform, to transition people out of disadvantage by addressing poverty, unfulfilled capabilities and social exclusion. This study explores how three Work Integration Social Enterprises (WISEs) in Australia help to realise wellbeing for their employees by mapping their micro-geographical experience of wellbeing. By mapping the sites within a social enterprise where wellbeing is realised, we provide a practical, empirical and replicable methodology that is useful for gaining insights into where and how wellbeing realisation occurs. This situates wellbeing as an upstream place-based resource likely to influence downstream health outcomes.
\end{abstract}

Key words: wellbeing, social enterprise, micro-geography, relational space, work.

\section{Introduction}

In recent decades, governments have come to promote social enterprises as a method of welfare reform, to transition people out of disadvantage by addressing poverty, unfulfilled capabilities and social exclusion (Barraket, 2013, Teasdale, 2010). Despite growing promotion and public investment, relatively little is known about how and in what contexts social enterprises produce wellbeing. This paper explores how three Work Integration Social Enterprises (WISE) help to realise wellbeing for their employees by mapping the microgeography within social enterprises, guided by spaces of wellbeing theory (Fleuret and Atkinson, 2007).

Social enterprise is variously understood, defined and enacted in different countries and work contexts (Teasdale et al., 2013). Here, social enterprises are understood as organisations that combine a social mission with the pursuit of financial sustainability and self-sufficiency via trading activity (Abbott et al., 2019). WISEs specifically aim to provide employment and work experience as a pathway into the open labour market (Spear and Bidet, 2005). In the study reported here, WISE employees experience complex disadvantage including intellectual or physical disability, mental ill-health, financial and social inequity. The work 
experience for employees includes recycling, catering and market gardening which are common WISE activities (Roy et al., 2017).

Individual studies and reviews indicate positive associations between social enterprise and mental health, health behaviours and social capital (Elmes, 2019, Mason et al., 2015, Roy et al., 2014). However, the study of social enterprise health impacts is only beginning, with Roy and Hackett (2017) recently concluding there is 'a clear need for more empirical research to better understand the causal mechanisms at work through social enterprises' (p.461). Emergent conceptual models linking social enterprise and health outcomes align with those used to evaluate complex public health interventions (Macaulay et al., 2017; Roy et al., 2014). These propose that social enterprise has the potential for upstream social effects that influence health downstream (Roy and Hackett, 2017).

Available literature suggests that social enterprises affect the social conditions for wellbeing by addressing: pathways into education and employment - with associated benefits including income and self-efficacy (Barraket and Archer, 2010, Roy et al., 2017); sources of health inequity, such as food insecurity (Gibson-Graham and Cameron, 2007); social capital development between people from diverse groups (Cheng, 2015, Evans and Syrett, 2007); community-level benefits through revitalising local economies in locationally disadvantaged areas (Berkes and Ross, 2013, Eversole et al., 2013); and reconfiguring of public and private spaces to improve civic, social and economic participation (Barraket and Archer, 2010, Munoz et al., 2015).

While these studies describe the wellbeing effects of social enterprises, they tend to demonstrate little about how social enterprises influence outcomes (Agafonow, 2018; Suchowerska et al., 2019). Further, Hall (2010) notes those assessing health impacts of social initiatives, can be tempted in multiple directions, addressing physical, mental and social indicators, which makes measurement unwieldy. We respond to these constraints by focusing on wellbeing and examining how it realises in and from WISEs by adopting a microgeographical analysis of their contextual conditions and effects.

Wellbeing, understood here as 'what constitutes a good and flourishing life' (Atkinson and Scott, 2015), is useful for exploring WISE impacts because it bridges social and health issues. In this respect, wellbeing resonates with a social model of health, which locates health 
experiences within social contexts (Cattell et al., 2008). By considering three similar WISE organisations, we explore the contextual features of social enterprises that help to realise people's experiences of wellbeing.

We apply spaces of wellbeing theory which derived from a multi-disciplinary literature review. The theory is applied because it aligns with the 'holism and intersectorality' of hybrid settings that address health improvement more broadly (Fleuret and Atkinson, 2007). Wellbeing is proposed as realising in and through relational spaces bringing: social integration (making and maintaining social connections and networks); capability (selfactualisation); security (ontological security (Giddens, 1991) and physical, or mental safety); and therapy (access to wellness and recovery). These effects are inter-related, with wellbeing realising as a fluid process shaped by social, spatial and temporal contexts (Atkinson, 2013).

Geographers emphasise relationships between health, places and spaces which produce and reproduce health experiences (Jones and Moon, 1993, Litva and Eyles, 1995). Examples include therapeutic landscapes (Kearns and Gesler, 1998) and spaces of care (Conradson, 2005) where places form/reform through constellations of human, non-human and material entities. Specifically applying spaces of wellbeing theory to explore wellbeing effects, researchers have considered art (Atkinson and Robson, 2012), dance classes (Atkinson and Scott, 2015), supported homes and drama clubs for people with intellectual disability (Hall, 2010) and care farms (Rotheram et al., 2017).

Despite growing interest in health and non-traditional spaces, and evidence that social enterprise can address place-related social vulnerabilities (Galea et al., 2005; Teasdale, 2012), the 'geographical research agenda for social enterprise' highlighted a gap in research on social enterprises, space/place and wellbeing (Muñoz, 2010). Insofar as social enterprise research has examined spatial issues, its focus has been on rural markets and resource access challenges (Smith and McColl, 2016). Here, we build on a case study by Munoz et al. (2015), which explored how social enterprises function as space-health assemblages.

Applying the idea of therapeutic assemblage (Gesler, 2003, Foley, 2011), Munoz et al. (2015) depict social enterprise as a relational outcome composed from material structure(s), socioeconomic context and the individuals who pass through, experience and shape social enterprise spaces. Others have applied geographical methodologies to expand understanding 
of the relational geographies of disability, while simultaneously problematising the concept of 'able-body' (Hall and Wilton, 2017). Re-conceptualisations of disability reflect broader geographical theories of space, in particular Massey (1985) who argues that space is an outcome of social interaction, regardless of impairments. This conception of spaces and place is intimately linked with the provision of space as emergent, fluid and performative (Jones, 2009). The study presented here contributes to this growing literature by mapping the spaces that help to realise wellbeing within the geo-organisational contexts of three social enterprises.

Methodologically, the study deploys a qualitative GIS approach, which has growing interest in mixed methods research (Hawthorne et al., 2015, Jung and Elwood, 2010, Kwan and Ding, 2008). Qualitative GIS harnesses qualitative ways of knowing alongside the spatial visualisation and analysis capabilities of GIS. In this way, partial understandings from multiple epistemic sources can productively inform one another (Elwood, 2010, Jones and Evans, 2012).

This paper has two research questions: 1) can micro-geographies highlight where wellbeing realises (and does not) for social enterprise employees? and 2) by empirically mapping where (and where not), can we extend understanding of how wellbeing realises? Exploring where and how wellbeing realises provides empirical insights about how social enterprises enable impact.

\section{Materials and Methods}

Linking wellbeing to physical locations within a social enterprise was done by geo-tagging mixed qualitative data, facilitating the production of a wellbeing micro-geography (BrennanHorley and Gibson, 2009, Kamstra et al., 2019) in a 'gathering together of socio-spatial components' (Anderson and McFarlane, 2011) in relational space. This was then explored using grounded visualisation (Knigge and Cope, 2006) to examine how wellbeing realises at the micro-geographical scale. Ethical approval was from Swinburne University (2017/079; $02 / 05 / 2017)$.

The WISEs in this study are located in two regional cities (service centres with $80-100,000$ population) in the States of Victoria and Tasmania, Australia. The included organisations (Table 1) represent a sample where researchers had established relationships. All are non- 
profits and one (AssistAll) is also a registered charity. Employees receive income through a combination of direct-to-employee payments from the Australian National Disability Insurance Scheme (NDIS) (Green et al., 2017) and a variable payment based on staff assessment of their competence at work-tasks. Employees are considered to be supported workers with the intention of preparing them for mainstream workplaces.

Table 1 Characteristics of the Work Integration Social Enterprises

\begin{tabular}{|l|l|l|l|}
\hline Social Enterprises & \multicolumn{1}{|c|}{ Setting 1: Farm } & Setting 2: Catering & \multicolumn{1}{|c|}{ Setting 3: AssistAll } \\
\hline Goods \& services & $\begin{array}{l}\text { Produce to restaurants, onsite } \\
\text { kitchen, vegetables for public sale, } \\
\text { art studio, light manufacturing, } \\
\text { assembly, packaging, courier and } \\
\text { mail service, fleet car washing, } \\
\text { garden maintenance. }\end{array}$ & $\begin{array}{l}\text { Food catering to } \\
\text { organisations and } \\
\text { individuals }\end{array}$ & $\begin{array}{l}\text { Produce timber products, } \\
\text { clothing recycling, mailouts, } \\
\text { print finishing, assembly, data } \\
\text { entry, catering, room-hire. }\end{array}$ \\
\hline N. Employees & 110 & 50 & 51 \\
\hline $\begin{array}{l}\text { N. Supervisors (full } \\
\text { or part-time) }\end{array}$ & 10 & 4 & 9 \\
\hline $\begin{array}{l}\text { Suburb deprivation } \\
\text { (percentile) }\end{array}$ & 8 th & 13 th & 43 rd \\
\hline
\end{tabular}

Table 1 - This table shows the Australian Socio-Economic Indexes for Areas (SEIFA) for each WISE. The Index is compiled by combining attributes that reflect disadvantage including low income, high unemployment and relatively unskilled occupations. A lower score on the index indicates a higher level of disadvantage (ABS Census of Population and Housing: Socio-Economic Indexes for Areas presented in profile.id.com.au).

\section{Data collection}

Data were collected in two phases: at Phase 1, data concerning wellbeing in relation to physical locations were collected using participant observation, semi-structured interviews and go-along interviews. Observations were collected via field notes and sketches during 80 hours per social enterprise over four months. Individual semi-structured interviews lasted around 60 minutes each, and were held with four staff in paid supervisory roles (henceforth supervisors) at each enterprise. These explored where supervisors believed wellbeing was/is realised.

'Go-along' interviews with those intended to benefit from social enterprise (henceforth employees) lasted around 90 minutes and involved conversations between an individual employee and a researcher, on an employee-led walk around the social enterprise (Farm $n=4$; Catering $n=5$; AssistAll $n=5$ ). Interviewees were identified by researchers and supervisors, guided by judgements about impacts on employees and capacity for informed consent. Employees highlighted where they go each day and their experience of wellbeing at different 
sites (e.g. individual locations such as rooms). During the go-alongs, places and objects stimulated employee story-telling and commentary in relation to different locations. Goalongs encourage expression through their relative informality and movement (Carpiano, 2009, Ottoni et al., 2016).

Mixed methods were essential because participants experiencing disadvantage can be unwilling or unable to participate in traditional research methods. Ultimately, we integrated participant observations with supervisor and employee interview data. Thus, resulting data includes researcher observations, representations of employees' experiences but also how the supervisors assume employees experience wellbeing, with no single method biasing the findings.

At Phase 2, following analysis and mapping (see below) of Phase 1 data, focus groups were held at the social enterprises, to verify and extend findings. Each included 2-4 participants as larger groups could not be released from work simultaneously. Some focus groups were mixed, while others had solely supervisors or employees. Total number of participants was: Farm (12), Catering (9), AssistAll (11). Focus groups used two means to engage participants with Phase 1 findings: i) participants plotted where they thought wellbeing realised on social enterprise maps; and/or ii) participants assigned wellbeing to photographs of individual social enterprise sites (e.g. rooms). Following this, researchers showed their micro-geography maps of Phase 1 findings and then facilitated discussion of similarities and differences between the two sets of mapping. Focus groups were 40-120 minutes and audio-recorded.

\section{Analysis and Mapping}

All data were de-identified, transcribed and uploaded into NVivo. Deductive analysis was conducted using a previously tested coding frame (Munoz et al., 2015) (Table 2), but open to new issues. To ensure consistency, three researchers coded all data. Original floor plans of each social enterprise provided an initial guide of physical locations where wellbeing might realise, but multiple micro-spaces - at varying spatial scales - also emerged. This led to physical locations being coded at varying spatial scales, i.e. relating to: micro (specific features e.g. bench), meso (e.g. rooms or physical spaces eg. garden), and macro (whole social enterprise) scale. 


\begin{tabular}{|l|l|l|l|}
\hline Capability & Integration & Security & Therapy \\
\hline $\begin{array}{l}\text { Physical activity/ } \\
\text { building strength }\end{array}$ & $\begin{array}{l}\text { People in existing } \\
\text { networks of social } \\
\text { relations }\end{array}$ & $\begin{array}{l}\text { Building comfort with } \\
\text { risky life situations }\end{array}$ & $\begin{array}{l}\text { Physical, mental or } \\
\text { emotional recovery or } \\
\text { healing }\end{array}$ \\
\hline $\begin{array}{l}\text { Technical skills, } \\
\text { knowledge, experience }\end{array}$ & $\begin{array}{l}\text { People making new } \\
\text { social relations }\end{array}$ & $\begin{array}{l}\text { Security and support from } \\
\text { trusted people }\end{array}$ & $\begin{array}{l}\text { Feelings of self being } \\
\text { oorthwhile }\end{array}$ \\
\hline $\begin{array}{l}\text { Life skills, knowledge, } \\
\text { experience }\end{array}$ & $\begin{array}{l}\text { Networks/ connections } \\
\text { helping to solve } \\
\text { problems }\end{array}$ & $\begin{array}{l}\text { Escape from negative } \\
\text { external influences/forces }\end{array}$ & $\begin{array}{l}\text { Exposure to discourses } \\
\text { of recovery/healing }\end{array}$ \\
\hline $\begin{array}{l}\text { Independent } \\
\text { thinking/problem- } \\
\text { solving }\end{array}$ & $\begin{array}{l}\text { Exposure to discourses } \\
\text { or practices of inclusion }\end{array}$ & $\begin{array}{l}\text { Facilitating encounters } \\
\text { with difference, change or } \\
\text { the unknown }\end{array}$ & $\begin{array}{l}\text { Finding work that is } \\
\text { physically or } \\
\text { psychologically suited }\end{array}$ \\
\hline $\begin{array}{l}\text { Accomplishment, } \\
\text { achievement or self- } \\
\text { actualisation }\end{array}$ & $\begin{array}{l}\text { Belonging to a team or } \\
\text { group }\end{array}$ & $\begin{array}{l}\text { Understanding how to } \\
\text { negotiate routine and } \\
\text { boredom }\end{array}$ & Nurturing identity repair \\
\hline Creativity & $\begin{array}{l}\text { Negotiating interpersonal } \\
\text { conflict }\end{array}$ & $\begin{array}{l}\text { Gaining security due to } \\
\text { continuity and consistency }\end{array}$ & $\begin{array}{l}\text { Expressions of sensory } \\
\text { pleasure }\end{array}$ \\
\hline Self-confidence & $\begin{array}{l}\text { Building interpersonal } \\
\text { trust }\end{array}$ & $\begin{array}{l}\text { Actual physical or mental } \\
\text { safety }\end{array}$ & Fun and laughter \\
\hline
\end{tabular}

To spatially represent wellbeing mentions (with 'mention' defined as an item of qualitative data), a geodatabase was created in ArcGIS by digitising the site locations and connecting the number of mentions for each wellbeing aspect to that location (Kamstra et al., 2019) thereby transferring wellbeing 'geo-narratives' (Kwan and Ding, 2008) into a simplified geographic format.

Wellbeing densities were computed as quartic kernels, weighted by the number of mentions for each wellbeing aspect (Table 3). Default kernel radii were defined by ArcGIS in relation to each social enterprise extent. Output densities were symbolised as percentages using natural breaks, with darker shades representing greater concentration. To create the $3 \mathrm{D}$ surfaces, a kernel density of total wellbeing mentions was calculated for each organisation. These total wellbeing layers were visualised in ArcScene, exaggerating the 2D results into 3D peaks. Resulting sets of micro-geographical maps reveal spatial relationships between wellbeing and sites that were previously hidden.

\section{Results}

Here, we present maps that reveal where wellbeing realised for social enterprises and some discussion of each. The discussion is based on the mixed methods 'mentions' underpinning the maps and we include quotes to contextualise how wellbeing realises in relational space. As consistencies in wellbeing realisation were found across social enterprises, to avoid repetition, we provide most detail for Farm and only key evidence that verifies or extends this, for Catering and AssistAll. 
Table 3 - Mentions of wellbeing coded to social enterprise sites*

\begin{tabular}{|c|c|c|c|c|c|}
\hline Micro-Space & $\begin{array}{l}\text { Capability } \\
(n=)\end{array}$ & Integration $(n=)$ & $\begin{array}{l}\text { Security } \\
(\mathrm{n}=)\end{array}$ & $\begin{array}{l}\text { Therapy } \\
(n=)\end{array}$ & Total \\
\hline \multicolumn{6}{|l|}{ Farm } \\
\hline Garden & 61 & 55 & 22 & 10 & 148 \\
\hline Carwash & 13 & 15 & 4 & 7 & 39 \\
\hline Blockroom & 9 & 8 & 14 & 3 & 34 \\
\hline $\begin{array}{l}\text { Supervisor's } \\
\text { office }\end{array}$ & $\mathbf{0}$ & 1 & 12 & 11 & 24 \\
\hline Woodwork & 15 & 3 & $\mathbf{0}$ & 1 & 19 \\
\hline Lunch-room & 1 & 10 & 3 & 1 & 15 \\
\hline Produce & 5 & 7 & $\mathbf{0}$ & $\mathbf{0}$ & 12 \\
\hline Training & 6 & 2 & 1 & $\mathbf{0}$ & 9 \\
\hline Deliveries & 5 & 1 & 2 & $\mathbf{0}$ & 8 \\
\hline Kitchen & $\mathbf{0}$ & 4 & 1 & 2 & 7 \\
\hline Welding & 5 & $\mathbf{0}$ & 1 & $\mathbf{0}$ & 6 \\
\hline All of Farm* & 11 & 4 & 13 & 6 & 34 \\
\hline Total & 149 & 125 & 80 & 46 & \\
\hline \multicolumn{6}{|l|}{ Catering } \\
\hline Micro-Space & $\begin{array}{l}\text { Capability } \\
(n=)\end{array}$ & $\begin{array}{l}\text { Integration } \\
(n=)\end{array}$ & $\begin{array}{l}\text { Security } \\
(n=)\end{array}$ & $\begin{array}{l}\text { Therapy } \\
(n=)\end{array}$ & Total \\
\hline $\begin{array}{l}\text { Supervisor's } \\
\text { office }\end{array}$ & 3 & 2 & 11 & 6 & 22 \\
\hline $\begin{array}{l}\text { Sandwich- } \\
\text { making }\end{array}$ & 10 & 2 & 4 & 2 & 18 \\
\hline Deliveries & 5 & 10 & 3 & $\mathbf{0}$ & 18 \\
\hline Boxroom & 1 & $\mathbf{0}$ & 3 & 5 & 9 \\
\hline Couches & $\mathbf{0}$ & 1 & 5 & 3 & 9 \\
\hline Bench 7 & 5 & $\mathbf{0}$ & 3 & $\mathbf{0}$ & 8 \\
\hline $\begin{array}{l}\text { All of Admin } \\
\text { Area* }\end{array}$ & 2 & 5 & 9 & 4 & 20 \\
\hline All of Kitchen* & 48 & 15 & 27 & 4 & 94 \\
\hline Total & 86 & 38 & 65 & 31 & \\
\hline \multicolumn{6}{|l|}{ AssistAll } \\
\hline Micro-Space & $\begin{array}{l}\text { Capability } \\
(n=)\end{array}$ & $\begin{array}{l}\text { Integration } \\
(n=)\end{array}$ & $\begin{array}{l}\text { Security } \\
(n=)\end{array}$ & $\begin{array}{l}\text { Therapy } \\
(n=)\end{array}$ & Total \\
\hline Deliveries & 12 & 7 & 7 & 3 & 29 \\
\hline Worktables & 15 & 4 & 4 & 3 & 26 \\
\hline Diningroom & 2 & 14 & 5 & 3 & 24 \\
\hline Boardroom & 4 & 2 & 5 & 1 & 12 \\
\hline $\begin{array}{l}\text { Supervisor's } \\
\text { office }\end{array}$ & $\mathbf{0}$ & 2 & 9 & 1 & 12 \\
\hline Training & 1 & 1 & 4 & 3 & 9 \\
\hline Toilets & $\mathbf{0}$ & 1 & 3 & 4 & 8 \\
\hline Laundry & 7 & 0 & 0 & $\mathbf{0}$ & 7 \\
\hline Pallet-making & 6 & $\mathbf{0}$ & 1 & $\mathbf{0}$ & 7 \\
\hline Ironing area & 6 & $\mathbf{0}$ & 1 & $\mathbf{0}$ & 7 \\
\hline Shop & 7 & $\mathbf{0}$ & 0 & $\mathbf{0}$ & 7 \\
\hline Manager & $\mathbf{0}$ & $\mathbf{0}$ & 6 & $\mathbf{0}$ & 6 \\
\hline
\end{tabular}




\begin{tabular}{|l|l|l|l|l|l|}
\hline Kitchen & $\mathbf{0}$ & $\mathbf{0}$ & 6 & 0 & 6 \\
\hline All of Woodshop* & 5 & 0 & 2 & 0 & 7 \\
\hline $\begin{array}{l}\text { All of } \\
\text { Workroom* }\end{array}$ & 1 & 6 & 10 & 4 & 21 \\
\hline Total & 69 & 46 & 62 & 28 & \\
\hline
\end{tabular}

*Includes only sites with $>=$ four mentions.

\section{Setting 1: Farm}

Farm is a $10,386 \mathrm{~m}^{2}$ area comprised of a mix of permanent buildings, portables, open air structures and a large garden. A central building includes a carwash, lunchroom and woodwork site, with other work sites radiating outward. Figure 1 maps Farm's wellbeing geography by its four constituent aspects in a 2D density format, with a 3D rendering of all aspects combined at top right.

Four unique micro-geographies resulted, each with differing spreads and intensities.

Capability spread across the most sites while therapy occupied the least. Security clustered quite strongly across two non-proximate sites while therapeutic concentrations occurred in adjacent locales. The garden registered as the strongest 3D peak, indicating its significance to wellbeing. To better understand the contribution of specific sites, we move now to discuss the details of each wellbeing aspect. 


\section{Farm}
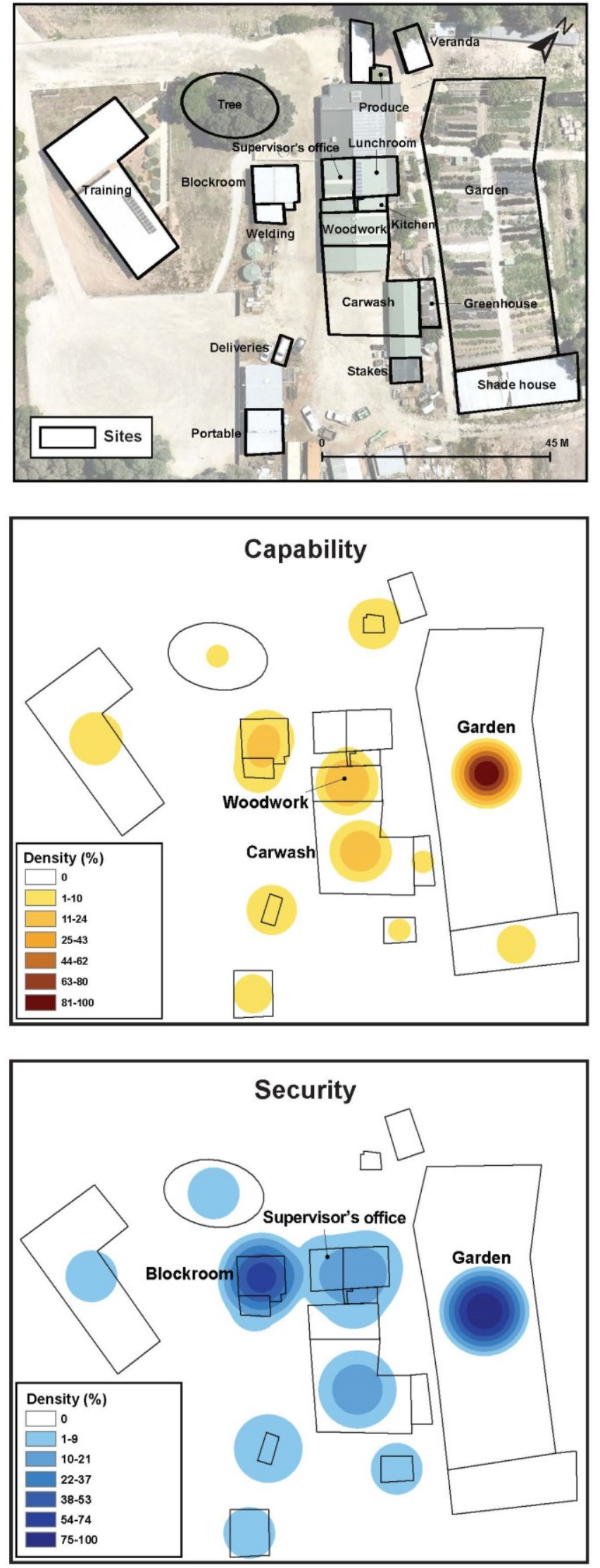
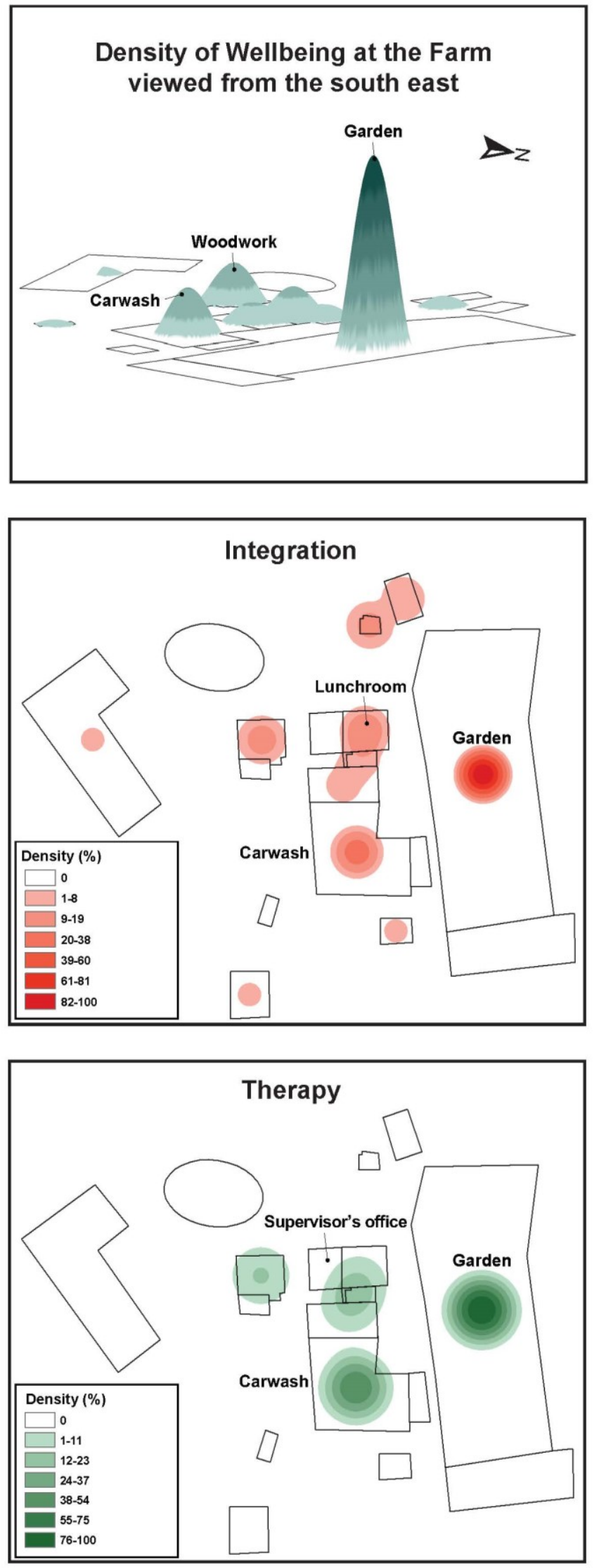

Figure 1 - Micro-geography of wellbeing mentions at Farm. 
Capability: The garden (61), woodwork (15) and carwash (13) have most mentions coded to capability. Examining underpinning data reveals reasons. The garden hosts multiple worktasks and an apparent progression from directed basic (e.g. weeding) to complex autonomous, tasks (e.g. building paths or harvesting seeds). Availability of multiple task options alleviates boredom as employees can move between tasks/sites, thereby facilitating 'progress' through tasks in which they can achieve mastery, building self-confidence:

You start off new and you learn the ropes, and then you specialise on an area...nowadays, I specialise in the harvest... and then I've got more confidence. I did an admin course and did the public speaking thing. I could never had done it at school. [Farm_employee_1]

The woodwork site and carwash facilitate application of fine, complex and sometimes creative skills. Performance at car-washing is subject to wider assessment by external client organisations and by employees being selected for the added responsibility of driving the cars to clients in the community. These aspects expose employee achievement not only to peers, but to the whole community and this 'being seen to be' achieving was found significant to capability realisation. Employees gained strength from being 'publicly' valued:

My brother asked one of the people from Farm "do you know Micky?”. He does. Then he asked how I was going at Farm and he said I was one of the good employees (smiles proudly). [Farm_employee_2]

Availability of multiple task/sites at Farm allowed employees to discover tasks they have aptitude for and comfort with; for example, perhaps related to varying cognitive and mobility characteristics, some employees were comfortable with and skilled at, routine tasks of the blockroom such as folding laundry. Others selected more active, problem-solving and cognitively challenging tasks/sites; while others moved between tasks, sometimes depending on their health or mood. Linked to progression through tasks, 'checking-off' achievement of goals set through regular development plans, was another way of employees realising capability from formal acknowledgement of advancement. Capability also realised through peer-mentoring strategies where employees could transfer knowledge and skills to each other, benefiting from learning and teaching experiences.

Integration: The garden (55), carwash (15) and lunchroom (10) have the most integration mentions. New employee-employee and volunteer-employee relationships form in the 
garden, developed from working collaboratively. Sometimes strategic pairing of people was coupled with strategic deployment in physical space to facilitate interaction:

If you had two people on a row, they'll end up both at different ends, not necessarily talking to each other. If you put three or four on, they all sit there together and they're all weeding along together. It's funny how it works. [Farm_supervisor1]

On some days, multiple people from different backgrounds work in the garden, including visiting students, volunteers and employees. This provides opportunities to interact with new people, but only if working on joint tasks. Lunchroom interactions tend to involve established friendships. New connections tended to derive from team-work and problem-solving; for example, at carwash where team-members must negotiate who will clean, polish and detail. Some employees shunned interaction; for example Kevin, who generally selected to sit alone, painting mine stakes, and stopping at specific times, to watch trains passing at the end of the garden.

Security: The garden (22), block-room (14) and supervisor's office (12) had highest security. Routines and repeated practices were features of the garden and block-room - the latter, a site of repetitive laundry-folding and painting mining stakes. For some employees with mobility or cognitive challenges, who regularly work there, the block-room provides an enclosed safe space and routines, along with feelings of mastery.

Even employees who mostly work at other sites sometimes chose the block-room if they felt anxious or upset - citing the repetitious work as providing a sense of calm and safety. Trust in gaining support is associated with security from the supervisor's office:

I just go to Georgie [supervisor] ...I just talk to her and that ...just like anything...what I've been doing throughout the week [Farm_employee_2]

Data reveal that employees meet with their supervisor for support with work and for issues in other aspects of their life, such as finding accommodation. Supervisors sometimes provided their mobile phone numbers so employees can reach them out-of-hours.

Therapy: The supervisor's office (11), garden (10) and carwash (7) had most therapy mentions. Employees go to the office to recover or get support if they are upset or ill. 
Varying mentions for the garden highlighting enjoyment of its greenery and peacefulness: "It's nice and peaceful. I enjoy it" [Farm_employee_2], contrasted with mentions at the carwash that related to fun and laughter, highlighting that employees gain therapeutic benefit from varied spaces.

\section{Setting 2: Catering}

Catering is a small building $\left(342 \mathrm{~m}^{2}\right)$ consisting of a kitchen, which hosts most ongoing activities, with the back office and box-room towards the rear (Figure 2). The four wellbeing aspects show a similar spatial spread, but differing intensities. Security registered most strongly toward the south, while capability skewed north east. Aggregated wellbeing peaked around the office and deliveries site. General wellbeing mentions were strongest in the kitchen but tapered off toward the rear. 

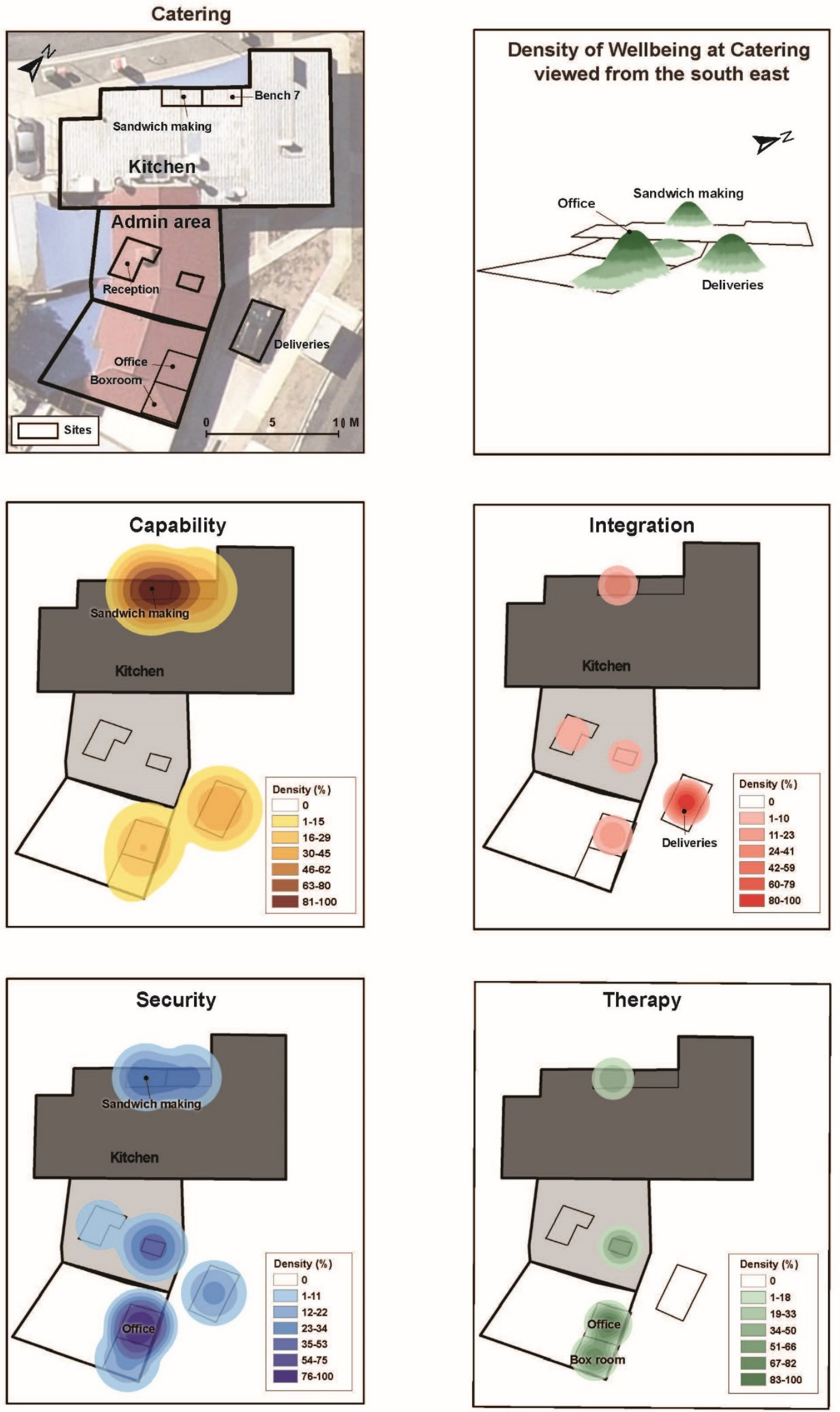

Figure 2 - Micro-geography of wellbeing mentions at Catering. 
Capability: The kitchen (48), including the sandwich-making site (10), had most capability mentions. As with Farm, these often relate to availability of multiple progressing tasks from vegetable paring through to using tools for time/quantity measurements when baking. A prominent feature here (also traced at Farm and AssistAll) was the practice of triaging employees to identify their aptitudes:

Well I would get them to peel carrots and potatoes - to see how they can work with their hands. If they cannot peel, you don't really want them to touch a sharp knife [Catering_supervisor_2]

Linked, and again traced at the other social enterprises, was data about the organisation providing a supportive environment to try new skills, thus 'pushing' employees to identify the limits of their self-actualisation:

He talks about how sometimes he makes mistakes. But its ok. This begins a conversation where everyone talks about how it's ok to make mistakes.

Chris [supervisor] says "you can always fix them, or you can learn”. All the employees agree. [Catering_observation]

A notable feature of the physical kitchen layout is that supervisors locate themselves to easily monitor newer or less skilled employees, with sites of greater skills and autonomy (sandwichmaking and bench 7 where pastries are made) located furthest from supervisors. Strategic pairing to realise capability from learning and teaching, found at Farm, was also exemplified:

It's good to see that they work together. It gives that one that's more experienced a bit more confidence that they can do things.

[Catering_supervisor_2]

Integration: With highest mentions, the kitchen (15) is a small physical site hosting multiple employees and supervisors, often working on time-delineated commercial food production. Co-operative team-work is maintained through verbal and embodied interactions. Next highest, the deliveries site (10) is where employees and supervisors meet to travel by van to community-based clients. Findings show that employees associate this site with interactions while travelling and with friendly community encounters: 
They are always so excited...No-one ever seems nervous. They get to come outside and speak to the customers...they might say "here's a feedback form. They might help put their food in the fridge."

[Catering_supervisor_1]

Security: Kitchen (27) mentions related to predictable routines. At times, this was a stressful site with deadlines and quality pressures, but employees drew on supervisory support and encouragement. As at Farm, the office (11) of employees' support worker was a place to gain strategies and encouragement for addressing work and life challenges.

Therapy: The office, with six mentions, provided recovery if employees were distressed or ill, while the box-room (5) provided a recovery space when employees were affected by stressful kitchen work. Its therapeutic effects realised from affording isolation from others (there is only physical space for one person) and via the repetitive, manual task of folding cardboard boxes.

\section{Setting 3 AssistAll}

AssistAll consists of two buildings, a $1230 \mathrm{~m}^{2}$ workshop (woodwork and pallet-making) and a $725 \mathrm{~m}^{2}$ workroom (worktables, supervisor's office and dining-room). A recycled clothing shop is at the front of the workroom and a deliveries site sits between the two (Figure 3). The 3D combined wellbeing density shows the highest crest on the deliveries site, with dual peaks sitting over the workroom. Most notable were the spatial extent of both security and therapy, each covering a large expanse of the workroom. Capability also registered there, but less extensively, peaking over the kitchen and worktables. 
Assist All

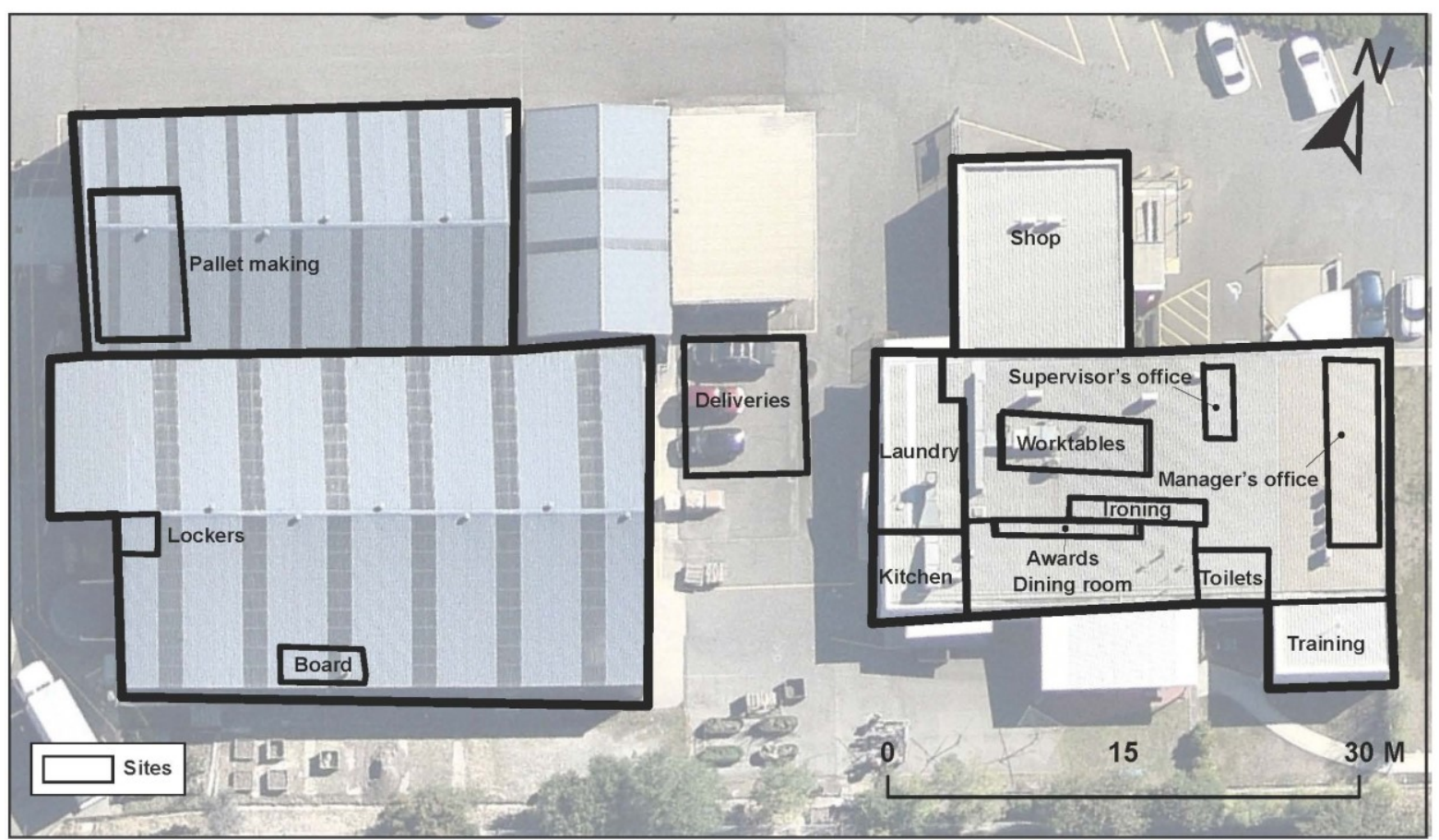

Density of Wellbeing at Assist All viewed from the south east
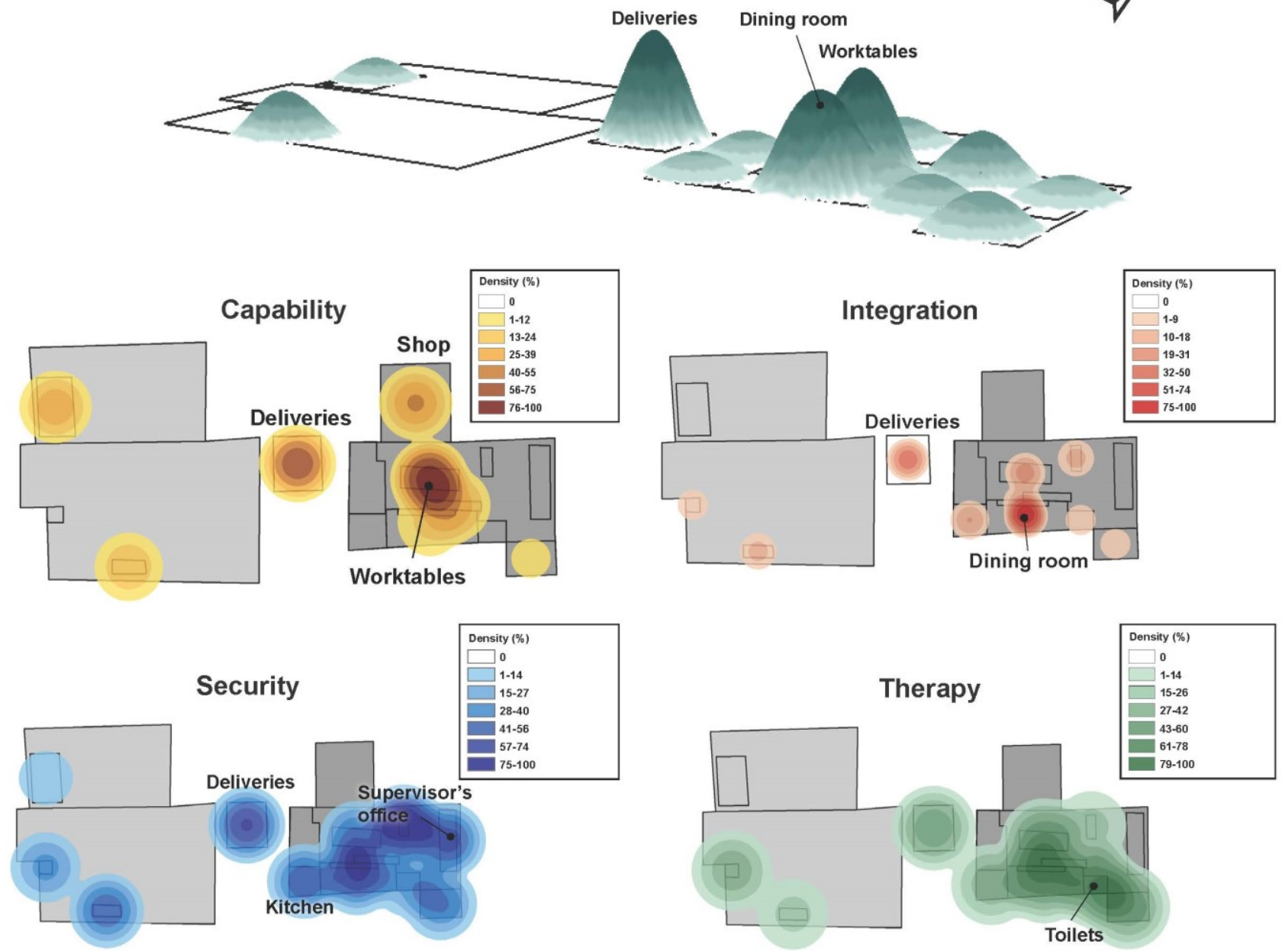

Figure 3 - Micro-geography of wellbeing mentions at AssistAll 
Capability: With highest mentions, the worktables (15) hosts employees undertaking intricate and complex tasks, including compiling mail-outs and fixing labels onto small objects such as keyrings. At the shop (7), employees undertake multiple tasks including sorting and ironing clothes and customer interaction. The deliveries site (12) was associated with feelings of achievement at being selected to travel out into the community. Different to Farm and Catering, sensitive to employee boredom, AssistAll has a policy of rotating employees through task/sites at three-monthly intervals.

Integration: The dining-room (14) and deliveries site (7) had highest integration mentions. Employees socialised with friends in the dining-room and, as with Catering, the deliveries site was associated with client interactions in the community:

Jordan's in today and he loves to go for a ride in the truck...they're generally well-accepted or people make a point of saying hello and talking to them - and they're not shy either... [AssistAll_supervisor_2]

Security: Mentions for the deliveries site (7) related to employees who carry out deliveries, on their own, in the community. Employees receive support before and during the deliveries (via phone) to make sure that they know what to do when outside of the social enterprise. As previously, the Managers' office (6) is a site where employees access support, while the kitchen (6) is associated with routines and support.

Therapy: The toilets (4) had highest mentions. The toilets were the only site useable by employees if they wanted to recover from upset by being alone. Much of AssistAll is openplan in its physical layout and there are few sites to attain solitude.

\section{Focus Groups}

Focus groups verified phase 1 findings. Layout and personnel reconfigurations had occurred at all organisations in the interim, resulting in changes to wellbeing realisation at different sites. At Catering, for example, employees discussed that the reconfigured reception area was sometimes a site of security because the support worker had relocated there. However, at arrival and break-times, the reception helped to realise integration as people communicated while movinginto and through the room. Box-making was also relocated to the reception area, which changed this activity from being solitary, to interactive. The lockers and outside 
seating areas had become sites where people sought solitude, although this was often difficult to achieve.

At AssistAll, a new sickroom was a place for recovery. It became used "as a quiet space, just a place to retreat if people are feeling a bit overwhelmed" [supervisor quote focus group].

Reconfiguration highlights the temporality and fluidity of wellbeing realisation; which was also raised as seasons changed. At Farm, in the spring-time when focus groups were held, the shade-house became significant to capability realisation as employees learned to plant and nurture seedlings. Original data, collected in autumn-winter, showed no mentions for the shade-house. Similarly, at AssistAll, employees noted that the outside 'firepit' was an integration site in cold winter months only.

Temporality is also relevant to individuals' 'journeys of wellbeing'. One employee who, at phase 1, expressed pride in her capability at sandwich-making, said at phase 2 that she was now bored with sandwiches and wanted to learn something new.

\section{Variations on wellbeing}

We were also interested in evidence of sites where realising wellbeing was either rarely mentioned or not realised. Sites with few mentions $(<4)$ were varied, but themes were: new sites (new café at Farm); 'passing-through' sites (original reception at Catering); and some due to seasonality (shade-house at Farm). Across the three social enterprises, we found 47 mentions coded as 'not wellbeing'. The highest number were 'not integration' $(n=27)$. These tended to arise where people were physically co-located, but not interacting, as here:

The driver comes into the kitchen and helps Zoe pack the food onto the trolley... the driver doesn't talk to any of the employees - but does talk to Zoe and Helen [supervisors]. (Catering_Observation)

Data coded 'not capability' (eight mentions) were about barriers to self-actualising; for example, supervisors having insufficient time to explain tasks or to explore new tasks with employees, due to times when the focus had to be on commercial production.

Data for 'not security' (seven mentions) related to situations where organisational or individual routines were disrupted, as here: 
The groups had been split into different jobs today because one of the supervisors was off sick and there were no offsite gardening jobs...The guys washing cars, and those folding [laundry] seem fine. However, the people that have been moved into jobs that they do not normally do, like painting stakes...seem a little agitated, there is not much conversation and they work alone. (Farm_observation).

Data coded to 'not therapy' (five mentions) were where people expressed either being tired, finding manual tasks too difficult or not enjoying working at a particular site. Mentions were simply coded as not contributing to wellbeing aspects and we cannot comment on effects on existing wellbeing.

\section{Discussion}

We found that a qualitative GIS approach helped to understand how wellbeing realises for work integration social enterprise employees, by initially showing where it realises. Mapping revealed previously hidden geographies of wellbeing at three social enterprises, each composed of aspects that came together in unique ways and at varying spatial scales. Including multiple settings and mixed methods data collection provides internal verification for the findings. The study suggested some consistent features of wellbeing realisation found (summarised in Figure 4).

Capability
- Multiple / progression of tasks
- Formal planning, goal-setting and checking
- Recognition of achievement
-'Being seen to be' achieving
- Opportunities for creativity
- Triaging for aptitude
- Support to try new things
- Strategic pairing for learning \& teaching
Integration
- Problem-solving and teamwork tasks
- Pro-social spaces
- Inclusion of people from diverse backgrounds
- Opportunities for encounters in the community
- Strategic deployment of people in physical space
- Strategic pairing to meet new people
- Sites with repetitive tasks
- Places to go for support

Figure 4 - How wellbeing realises in social enterprises

Unpacking the wellbeing aspects, starting with capability - the informal triaging of employee aptitudes is used by supervisors as the foundation for developing this aspect. Active strategies 
were then applied to help employees to self-actualise as fully as possible over time, including formal planning and strategic linking of people to work with each other. Farm and Catering employees moved around the work/sites as their aptitudes and preferences evolve. In contrast, AssistAll had developed a strategy of work rotation.

Vital to capability realisation, supervisors apply a supportive, but forceful narrative encouraging employees to try new tasks and not to worry about mistakes. Hosting a variety of work-tasks, checking off goal achievement and working with employees in sites where they are seen by others (such as open-plan rooms, the garden and in the community) assists employees with internalising their growing achievements. Exemplifying from carwash at Farm; there was achievement from becoming skilled to drive cars in the community, being trusted by supervisors, being seen by peers and from actually being observed driving cars in and by the wider community.

These efforts occur within a socio-cultural symbolic milieu, which suggests legitimate 'citizenship' arises from fulfilling on the neoliberal ingrained 'ethical obligation to work' (Evans and Wilton, 2019). In short, through their empathy with the social situations experienced by employees, and their applied strategies, supervisors at the social enterprises enable the employees to view themselves and be viewed by others as valuable in contemporary society. One question is whether supervisors intuitively apply their strategies, whether more socially-intuitive people are drawn to work at social enterprises or whether social enterprises, via their social-commercial hybridity, evolve a uniquely assembled prowellbeing space that shapes staff practices.

Considering social integration, traditionally pro-social spaces such tea-rooms would be considered helpful, but as Duff (2016) observed when examining social inclusion via cafes, such places often merely embed existing relationships. New and different relational spaces are required to facilitate the social intermingling that leads to new connections; for example, in this study, problem-solving together how to build a garden path or produce a well-cleaned car facilitated previously unrelated people to interact, as did strategic physical space configurations. These findings resonate with Atkinson and Robson (2012) discussions of communitas, where previously unrelated people are ephemerally united through 'liminal' cocreation activities that liberate them from past constraints, also inducing experiences of equality and trust. 
Suggesting the potential of social enterprises as community 'boundary-spanning' spaces, deliveries sites at Catering and AssistAll were found significant to employee integration. This aligns with literature about empathy and mutual learning benefits of 'brief encounters' between people with a disability or mental illness, and wider communities, facilitated through social enterprise and related activities (Evans and Wilton, 2019, Wiesel and Bigby, 2016). Considering features that help to realise security, the findings concur with but systematise and extend, Jahoda's (1981) proposal that time structure and regular activity are beneficial 'latent by-products' of work (p.189). Here, security encompasses notions of ontological security as well as physical safety. Employees' access to supportive supervisors was significant to their security. However, being constantly available e.g. via providing their personal phone numbers, is a heavy obligation and additional research could extend understanding of any trade-offs between supervisor wellbeing and supporting employee wellbeing (Houtbeckers, 2017). Our findings concur with Evans and Wilton (2019) that social enterprises can provide a form of secure social 'safety net' for employees.

Examining therapeutic spaces, the significance of the garden is consistent with literature on benefits of greenspace, including from community gardens (Kingsley et al., 2009). The finding that sites could be therapeutic in different ways was also noteworthy. While some appreciated the tranquillity and biophilic effects of the garden, others highlighted laughter and fun at the carwash, resonating with the rise of 'laughter therapies' (Ko and Youn, 2011). A surprising finding was therapy realisation at Catering's box-room and AssistAll's toilets both locations where benefit realised from solitude. The need for people to balance times of integration and sociality, with periods of being alone is confirmed by Littman-Ovadia (2019).

With regard to the literature on social enterprise and health, our findings resonate with existing research that WISEs can provide people-centred work and work training environments that contribute to individual health and wellbeing (Elmes, 2019, Roy et al., 2014). Responding to calls for greater explication of just how social enterprises produce wellbeing (Suchowerska et al., 2019), our micro-geographical analysis presents a novel means to expose the mechanisms and assemblages through which particular aspects of wellbeing emerge, empirically. Progressing work on visualising creativity in regional cities (Brennan-Horley and Gibson, 2009), this study suggests how maps and qualitative GIS can help to improve the environment in social enterprises to optimise wellbeing realisation, by 
helping to surface and make tangible, previously intangible and hidden qualitative properties. In revealing findings about 'not wellbeing', we provide reliability-checking that can be missing in studies that highlight purely positive social enterprise outcomes (Macaulay et al., 2018).

Taken together, we concur with Cattell and colleagues' (2008) conclusions of wellbeing needs for/from public places; in which people '...need a variety of spaces ... to meet a range of everyday needs, spaces to linger as well as spaces of transit; spaces which bring people together and spaces for escape.' (p.4).

\section{Limitations}

Numbers of mentions collected from different social enterprises are not open to quantitative benchmarking across physical settings or sites because different 'amounts' of data were necessarily collected at each, varying with participants and workplace features. Larger quantities of data were collected in relation to larger physical spaces, for example. This could be influenced by the relative ease, for researchers, of collecting observational data unobtrusively in larger spaces or potentially to employee and staff bias to reporting about larger physical spaces because more employees can work there. Consequently, the focus here is on insights provoked by considering spatial arrangements and the nature of mentions.

Findings are cross-sectional and mapping does not account for temporal changes such as those related to seasonality and space reconfiguration as raised at focus groups. Similarly, the employee 'wellbeing journey' over time was not captured in mapping. Employees are intended to transition into mainstream work, but in reality, there were few identified transitions. Farm provided some employees with jobs as staff members, over time - while AssistAll acknowledged potential boredom by rotating workers through different worksites. In the study, we did not explore wellbeing fluctuations as a fluid process, over time - such as what happens when an employee reaches maximum capability. Future studies should consider how mapping methodologies can intersect more with temporality. As social enterprises were not compared with mainstream workplaces, any unique impacts cannot be unequivocally established. 


\section{Conclusion}

The study advances knowledge about social enterprises, wellbeing and health. Using qualitative GIS to map the micro-geographies of wellbeing provides a novel way to engage stakeholders in data-driven insights about how intangible, difficult to quantify concepts, such as wellbeing, develop. While findings confirm that the social enterprises studied act as spaces of wellbeing, specific aspects of wellbeing were distributed unevenly across the sites. Furthermore, not everything that happens all the time, brings wellbeing and we found elements of 'not wellbeing'.

A novel set of insights emerged about features that contribute to realising wellbeing. This helps to inform social enterprises about designing for wellbeing outcomes. Additionally, findings support the idea that social enterprises provide a particular workplace type. One where people move through work-tasks and available locations, or even stay in the same place, but in relation to their personal and changing aptitudes, abilities and needs over time. This is indeed a truly socially-supportive workplace which focuses on deploying, developing and supporting talents and not simply allocating people to one job in one location for all time.

Regarding spaces of wellbeing theory, we admit to pushing the theory into a frame where wellbeing is categorised, a direction resisted by Atkinson and Scott (2015) with justification. However, in doing so, we have gone some way to providing a practical, empirical and replicable spatial methodology to gain insights into wellbeing realisation, that situates wellbeing as an upstream place-based resource likely to influence downstream health outcomes.

The study was limited to one country, particular settings and work integration social enterprises. Further studies could test the methodology for other social enterprise contexts. There is also potential to apply the methodology to mainstream workspaces thereby helping to elucidate similarities and differences in wellbeing realisation between social enterprise and mainstream work. In this respect the methodology provides a means for organisational level assessments where much current focus is on the individual's responsibility for their wellbeing at work. 


\section{Acknowledgements}

This work was funded through an Australian Research Council Discovery Project

DP170100388 (2017-2019). We would like to extend a special thank you to Viktoria Adler and Sherridan Emery for their valued contributions.

\section{References}

Abbott, M., Barraket, J., Castellas, E. I.-P., Hiruy, K., Suchowerska, R. \& Ward-Christie, L. 2019. Evaluating the labour productivity of social enterprises in comparison to SMEs in Australia. Social Enterprise Journal, 15, 179-194.

Anderson, B. \& McFarlane, C. 2011. Assemblage and geography. Area, 43, 124-127.

Atkinson, S. 2013. Beyond components of wellbeing: The effects of relational and situated assemblage. Topoi, 32, 137-144.

Atkinson, S. \& Robson, M. 2012. Arts and health as a practice of liminality: Managing the spaces of transformation for social and emotional wellbeing with primary school children. Health \& Place, 18, 1348-1355.

Atkinson, S. \& Scott, K. 2015. Stable and destabilised states of subjective well-being: dance and movement as catalysts of transition. Social \& cultural geography, 16, 75-94.

Barraket, J. 2013. Fostering the wellbeing of immigrants and refugees? Evaluating the outcomes of work integration social enterprise. Social Enterprise. Routledge.

Barraket, J. \& Archer, V. 2010. Social inclusion through community enterprise?: examining the available evidence. Third Sector Review, 16, 13-28.

Barraket, J., Douglas, H., Eversole, R., Mason, C., McNeill, J. \& Morgan, B. 2017. Classifying social enterprise models in Australia. Social enterprise journal, 13, 345 361.

Berkes, F. \& Ross, H. 2013. Community resilience: toward an integrated approach. Society and Natural Resources, 26, 5-20.

Brennan-Horley, C. \& Gibson, C. 2009. Where is creativity in the city? Integrating qualitative and GIS methods. Environment and planning A, 41, 2595-2614.

Carpiano, R. M. 2009. Come take a walk with me: The "Go-Along" interview as a novel method for studying the implications of place for health and well-being. Health \& Place, 15, 263-272.

Cattell, V., Dines, N., Gesler, W. \& Curtis, S. 2008. Mingling, observing, and lingering: Everyday public spaces and their implications for well-being and social relations. Health \& place, 14, 544-561.

Cheng, I.-H. 2015. Re-modelling and reconceptualising skills development in Cambodia: How are social enterprises preparing young people for successful transitions between learning and work? International Journal of Educational Development, 43, 134-141.

Conradson, D. 2005. Landscape, care and the relational self: therapeutic encounters in rural England. Health \& place, 11, 337-348.

Duff, C. 2016. Atmospheres of recovery: Assemblages of health. Environment and planning A, 48, 58-74.

Elmes, A. I. 2019. Health impacts of a WISE: a longitudinal study. Social Enterprise Journal, $15,457-474$.

Elwood, S. 2010. Thinking outside the box: engaging critical geographic information systems theory, practice and politics in human geography. Geography Compass, 4, 45-60. 
Evans, J. \& Wilton, R. 2019. Well Enough to Work? Social Enterprise Employment and the Geographies of Mental Health Recovery. Annals of the American Association of Geographers, 109, 87-103.

Evans, M. \& Syrett, S. 2007. Generating social capital? The social economy and local economic development. European Urban and Regional Studies, 14, 55-74.

Eversole, R., Barraket, J. \& Luke, B. 2013. Social enterprises in rural community development. Community Development Journal, 49, 245-261.

Fleuret, S. \& Atkinson, S. 2007. Wellbeing, health and geography: a critical review and research agenda. New Zealand Geographer, 63, 106-118.

Foley, R. 2011. Performing health in place: The holy well as a therapeutic assemblage. Health \& place, 17, 470-479.

Gesler, W. M. 2003. Healing places, Rowman \& Littlefield.

Gibson-Graham, J. \& Cameron, J. 2007. Community enterprises: imagining and enacting alternatives to capitalism [Paper in: Counter Alternatives. Palmer, Victoria (ed).]. Social Alternatives, 26, 20-25.

Giddens, A. 1991. Modernity and self-identity: Self and society in the late modern age, Stanford university press.

Green, C., Malbon, E., Carey, G., Dickinson, H. \& Reeders, D. 2017. Competition and collaboration between service providers in the NDIS. Centre for Social Impact, UNSW Sydney.

Hall, E. 2010. Spaces of wellbeing for people with learning disabilities. Scottish Geographical Journal, 126, 275-284.

Hall, E. \& Wilton, R. 2017. Towards a relational geography of disability. Progress in Human Geography, 41, 727-744.

Hawthorne, T. L., Solís, P., Terry, B., Price, M. \& Atchison, C. L. 2015. Critical Reflection mapping as a hybrid methodology for examining sociospatial perceptions of new research sites. Annals of the Association of American Geographers, 105, 22-47.

Houtbeckers, E. 2017. Researcher subjectivity in social entrepreneurship ethnographies: The entanglement of stories in a co-working cooperative for social innovation. Social Enterprise Journal, 13, 128-143.

Jahoda, M. 1981. Work, employment, and unemployment: Values, theories, and approaches in social research. American psychologist, 36, 184-191.

Jones, K. \& Moon, G. 1993. Medical geography: taking space seriously. Progress in human geography, 17, 515-524.

Jones, M. 2009. Phase space: geography, relational thinking, and beyond. Progress in human geography, 33, 487-506.

Jones, P. \& Evans, J. 2012. The spatial transcript: analysing mobilities through qualitative GIS. Area, 44, 92-99.

Jung, J. K. \& Elwood, S. 2010. Extending the qualitative capabilities of GIS: computer-aided qualitative GIS. Transactions in GIS, 14, 63-87.

Kamstra, P., Cook, B., Kennedy, M. D. \& Brennan-Horley, C. 2019. Qualitative GIS to relate perceptions with behaviors among fishers on risky, rocky coasts. The Professional Geographer, 71, 491-506.

Kearns, R. A. \& Gesler, W. M. 1998. Putting health into place: Landscape, identity, and well-being, Syracuse University Press.

Kingsley, J. Y., Townsend, M. \& Henderson-Wilson, C. 2009. Cultivating health and wellbeing: members' perceptions of the health benefits of a Port Melbourne community garden. Leisure studies, 28, 207-219. 
Knigge, L. \& Cope, M. 2006. Grounded visualization: integrating the analysis of qualitative and quantitative data through grounded theory and visualization. Environment and Planning A, 38, 2021-2037.

Ko, H. J. \& Youn, C. H. 2011. Effects of laughter therapy on depression, cognition and sleep among the community-dwelling elderly. Geriatrics \& Gerontology International, 11, 267-274.

Kwan, M.-P. \& Ding, G. 2008. Geo-Narrative: Extending Geographic Information Systems for Narrative Analysis in Qualitative and Mixed-Method Research. The Professional Geographer, 60, 443-465.

Littman-Ovadia, H. 2019. Doing-Being and Relationship-Solitude: A Proposed Model for a Balanced Life. Journal of Happiness Studies, 20, 1-19.

Litva, A. \& Eyles, J. 1995. Coming out: exposing social theory in medical geography. Health \& Place, 1, 5-14.

Macaulay, B., Mazzei, M., Roy, M. J., Teasdale, S. \& Donaldson, C. 2018. Differentiating the effect of social enterprise activities on health. Social Science \& Medicine, 200, 211-217.

Mason, C., Barraket, J., Friel, S., O'Rourke, K. \& Stenta, C.-P. 2015. Social innovation for the promotion of health equity. Health Promotion International, 30, ii116-iil25.

Massey, D. 1985. New directions in space. Social relations and spatial structures. Springer.

Munoz, S.-A., Farmer, J., Winterton, R. \& Barraket, J. 2015. The social enterprise as a space of well-being: an exploratory case study. Social Enterprise Journal, 11, 281-302.

Muñoz, S. A. 2010. Towards a geographical research agenda for social enterprise. Area, 42, 302-312.

Ottoni, C. A., Sims-Gould, J., Winters, M., Heijnen, M. \& McKay, H. A. 2016. "Benches become like porches": Built and social environment influences on older adults' experiences of mobility and well-being. Social Science \& Medicine, 169, 33-41.

Rotheram, S., McGarrol, S. \& Watkins, F. 2017. Care farms as a space of wellbeing for people with a learning disability in the United Kingdom. Health \& place, 48, 123 131.

Roy, M. J., Donaldson, C., Baker, R. \& Kerr, S. 2014. The potential of social enterprise to enhance health and well-being: A model and systematic review. Social Science \& Medicine, 123, 182-193.

Roy, M. J. \& Hackett, M. T. 2017. Polanyi's 'substantive approach'to the economy in action? Conceptualising social enterprise as a public health 'intervention'. Review of Social Economy, 75, 89-111.

Roy, M. J., Lysaght, R. \& Krupa, T. M. 2017. Action on the social determinants of health through social enterprise. CMAJ: Canadian Medical Association Journal, 189, E440.

Smith, A. M. \& McColl, J. 2016. Contextual influences on social enterprise management in rural and urban communities. Local Economy, 31, 572-588.

Spear, R. \& Bidet, E. 2005. Social enterprise for work integration in 12 European countries: a descriptive analysis. Annals of public and cooperative economics, 76, 195-231.

Suchowerska, R., Barraket, J., Qian, J., Mason, C., Farmer, J., Carey, G., Campbell, P. \& Joyce, A. 2019. An Organizational Approach to Understanding How Social Enterprises Address Health Inequities: A Scoping Review. Journal of Social Entrepreneurship, 1-25.

Teasdale, S. 2010. How can social enterprise address disadvantage? Evidence from an inner city community. Journal of Nonprofit \& Public Sector Marketing, 22, 89-107.

Teasdale, S., Lyon, F. \& Baldock, R. 2013. Playing with numbers: a methodological critique of the social enterprise growth myth. Journal of social entrepreneurship, 4, 113-131. 
Wiesel, I. \& Bigby, C. 2016. Mainstream, inclusionary, and convivial places: Locating encounters between people with and without intellectual disabilities. Geographical Review, 106, 201-214. 